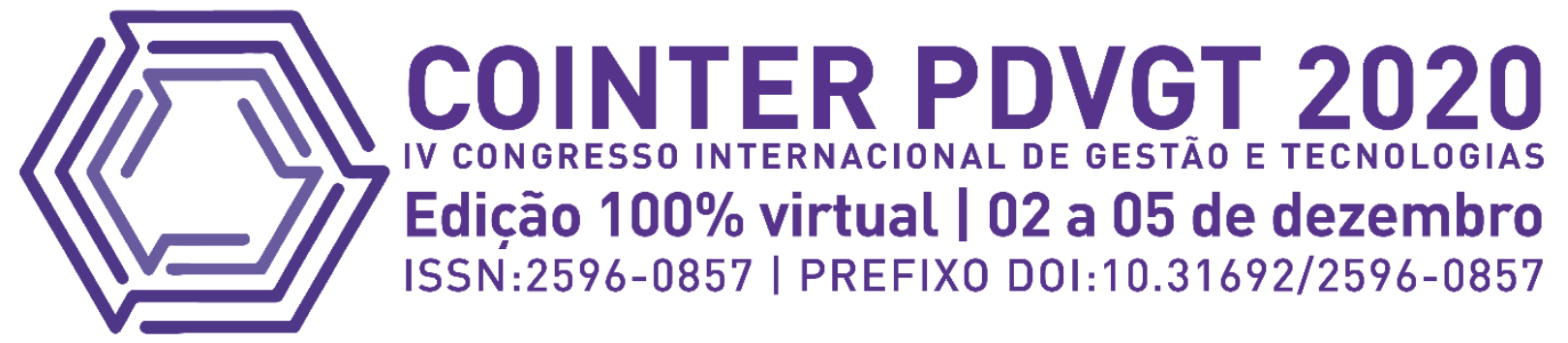

\title{
DESENVOLVIMENTO DE PROGRAMA COMPUTACIONAL PARA ESTIMATIVA DOS CUSTOS ENVOLVIDOS NO PROCESSO DE SOLDAGEM COM ELETRODOS REVESTIDOS (SMAW)
}

\author{
Apresentação: Comunicação Oral \\ João Victor Siqueira ${ }^{1}$; José Eduardo Ferreira de Oliveira² ${ }^{2}$ Tiago de Sousa Antonino ${ }^{3}$; José Dásio de Lira Júnior;
} Pablo Batista Guimarães ${ }^{5}$

DOI: https://doi.org/10.31692/2596-0857.IVCOINTERPDVGT.0066

\begin{abstract}
RESUMO
A soldagem é um dos processos de fabricação mais antigos da história e, atualmente, é uma das principais formas de união de matérias. Devido a Revolução Industrial, tal atividade se desenvolveu modernamente em meados do século XIX, incialmente com a soldagem por arco elétrico, onde se utilizava um eletrodo de grafite, que posteriormente foi substituído por um arame de metal. Com o passar do tempo, esse processo se tornou mais abrangente, dado o surgimento de diversos tipos de soldagem, dentre os quais se encontra o de soldagem a arco elétrico com eletrodos revestidos (Shielded Metal Arc Welding - SMAW), que promove a união de materiais a partir do calor gerado em um arco elétrico condicionado entre a extremidade do eletrodo metálico revestido e a superfície do objeto a ser soldado. Nesse sentido, dada a importância e flexibilidade desse processo de fabricação, é imprescindível estimar os custos. Dessa forma, o objetivo desta pesquisa foi criar um programa computacional, programado na linguagem VBA (Visual Basic for Application), para auxílio na determinação dos custos envolvidos no processo de soldagem com eletrodos revestidos (SMAW). O software, WELDVALUE, é composto por algumas equações que se adequam às informações inseridas pelo usuário e apresentam o custo unitário de cada seção (Mão de Obra, Metal de Adição e Energia Elétrica), bem como, ao final, o custo total.
\end{abstract}

Palavras-Chave: soldagem, custos, programa computacional, VBA.

\footnotetext{
${ }^{1}$ Mecânica Técnico, IFPE, siqueira300@hotmail.com.br

2 Professor Doutor, IFPE, joseferreira@ recife,ifpe.edu.br

${ }^{3}$ Professor Doutor, IFPE, tiagoantonino@ recife,ifpe.edu.br

${ }^{4}$ Professor Doutor, IFPE, josedasio@ recife,ifpe.edu.br

${ }^{5}$ Professor Doutor, IFPE, pabloguimaraes@ recife,ifpe.edu.br
} 


\section{INTRODUÇÃO}

Conforme MARQUES et. al. (2000), classicamente, a soldagem é considerada como um método de união, porém, muitos processos de soldagem ou variações destes são usados para a deposição de material sobre uma superfície, visando a recuperação de peças desgastadas ou para a formação de um revestimento com características especiais.

A soldagem é o mais importante processo de união de metais utilizados industrialmente. Este método de união, considerando em conjunto a brasagem, tem importante aplicação desde a indústria microeletrônica até a fabricação de navios (MODENESI et. al., 2011).

Tal processo de fabricação se caracteriza por sua grande flexibilidade, exercendo um papel de extrema importância na indústria e fora dela. A execução da soldagem envolve vários fatores variáveis que influenciam o custo total do procedimento como o uso de consumíveis (metal de adição, gás, fluxo e outros), o custo de pessoal e outros custos fixos, o gasto de energia elétrica, os custos de manutenção e a depreciação dos equipamentos e materiais de proteção, dentre outros (MODENESI, 2001).

Devido à sua diversidade, se faz cada vez mais necessário o auxílio de tecnologias para melhor compreender e facilitar este processo, bem como o conhecimento das equações analíticas que auxiliam na determinação dos custos envolvidos.

Portando, visando simplificar a influência de cada variável no custo do processo de soldagem com eletrodos revestidos (SMAW), foi elaborado um software programado em Visual Basic Application (VBA) para determinação dos custos de soldagem.

\section{FUNDAMENTAÇÃO TEÓRICA}

A soldagem a arco elétrico com eletrodo revestido (Shielded Metal Arc Welding SMAW), também conhecida como soldagem manual a arco elétrico, é o mais largamente empregado dos vários processos de soldagem. A soldagem é realizada com o calor de um arco elétrico mantido entre a extremidade de um eletrodo metálico revestido e a peça de trabalho (Figura 1). O calor produzido pelo arco funde o metal de base, a alma do eletrodo e o revestimento. Quando as gotas de metal fundido são transferidas através do arco para a poça de fusão, são protegidas da atmosfera pelos gases produzidos durante a decomposição do revestimento. A escória líquida flutua em direção à superfície da poça de fusão, onde protege 
o metal de solda da atmosfera durante a solidificação. Outras funções do revestimento são proporcionar estabilidade ao arco e controlar a forma do cordão de solda (MARQUES, 2007).

Figura 1: Processo de soldagem SMAW

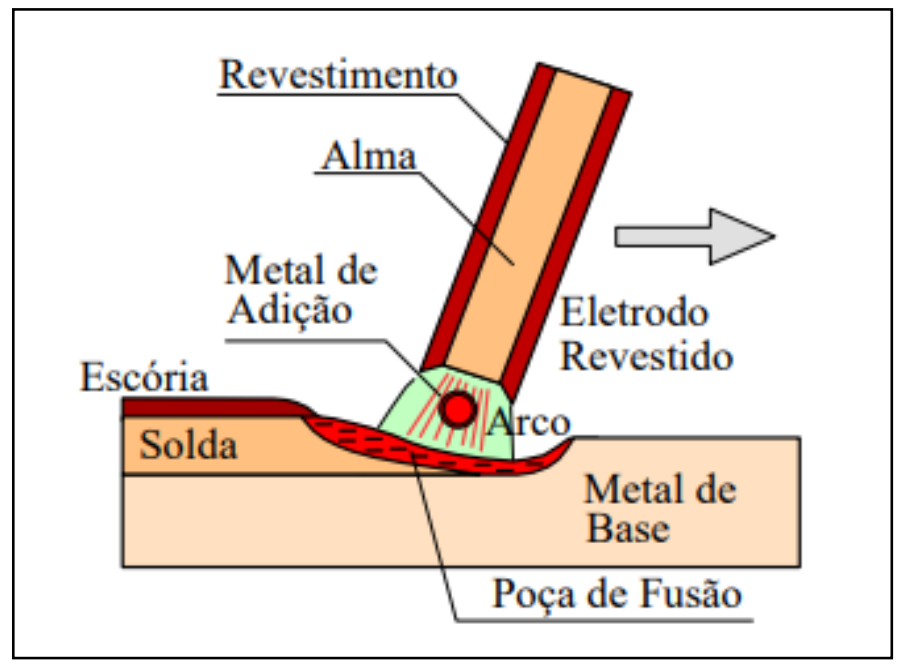

Fonte: FORTES (2004)

Em 1907, Oscar Kjellberg patenteou o processo de soldagem a arco com eletrodo revestido. Esses esforços culminaram no eletrodo revestido extrudado em meados dos anos 1920, melhorando muito a qualidade do metal de solda e proporcionando aquilo que muitos consideram o mais significativo avanço na soldagem por arco elétrico.

A busca contínua do aumento da produtividade propiciou o desenvolvimento de novos processos de soldagem. No entanto, ainda nos dias de hoje, é um processo muito empregado graças à sua grande versatilidade, ao baixo custo de operação, à simplicidade dos equipamentos necessários e à possibilidade de uso em locais de difícil acesso ou sujeitos a ventos.

As desvantagens do processo são a baixa produtividade, os cuidados especiais que são necessários no tratamento e manuseio dos eletrodos revestidos e o grande volume de gases e fumos gerados durante a soldagem. Mesmo assim, ainda continua a ser um processo de soldagem empregado na fabricação e montagem de equipamentos, na área de manutenção e reparos, em construções no campo, na soldagem por gravidade em estaleiros e de modo mais abrangente, na soldagem em geral de chapas de espessura variando de $3 \mathrm{~mm}$ a $40 \mathrm{~mm}$ (KOU, 1987; GUIMARÃES, 2011). 


\section{METODOLOGIA}

Inicialmente foi feita uma ampla pesquisa bibliográfica para melhor compreender o processo de soldagem, logo após foram feitas revisões e resolução de exemplos acerca das equações analíticas relacionadas aos custos de soldagem e, por fim, estudos acerca da programação em Visual Basic. Pode-se utilizar o software para determinação dos custos no processo de soldagem SMAW para juntas de topo e ângulo.

O programa computacional é composto por quatro equações que foram utilizadas tanto para a junta de topo, quanto para a junta em ângulo: custo da mão de obra (Eq. 1), custo do metal de adição (Eq. 2), custo da energia elétrica (Eq. 4) e o custo total (Eq. 5); e suas devidas resoluções serão efetuadas através de um programa escrito na linguagem Visual Basic Application (VBA), que é uma extensão encontrada no Microsoft Excel.

\section{Custo da mão de obra (CMO)}

$$
\text { CMO }(R \$)=(\text { Custo Unitário })(R \$ / h) \times \text { tempo de soldagem }(h)
$$

O custo unitário, mostrado acima, refere-se ao valor por hora que o trabalhador recebe, sendo assim, um valor variável. Já o tempo de soldagem pode ser encontrado através da relação entre o tempo de arco elétrico aberto e o fator de ocupação do soldador.

\section{Custo do metal de adição (CMA)}

$C M A(R \$)=$ massa do metal depositado $(\mathrm{kg}) \times$ custo do eletrodo $(R \$ / \mathrm{kg}) \quad$ (Eq. 2$)$

O referido custo do eletrodo possui valor variável, de acordo com o preço de mercado. Todavia, a massa do metal depositado (MMD) pode ser encontrada a partir da seguinte equação (Eq. 3):

$$
M M D(k g)=A \times L \times \rho
$$

Onde:

$\mathrm{A} \rightarrow$ Área da seção transversal da junta $\left[\mathrm{mm}^{2}\right]$

$\mathrm{L} \rightarrow$ Comprimento da solda [mm]

$\rho \rightarrow$ Densidade do material $\left[\mathrm{kg} / \mathrm{mm}^{3}\right]$

3. Custo da energia elétrica (CE) 
Onde:

$$
C E(R \$)=\frac{10 P E \times P E S \times t}{E}
$$

$\mathrm{PE} \rightarrow$ Preço da energia elétrica $[\mathrm{R} \$ \mathrm{kWh}]$

PES $\rightarrow$ Potência elétrica de saída [kW]

$\mathrm{t} \rightarrow$ Tempo de arco elétrico aberto [h]

$\mathrm{E} \rightarrow$ Eficiência elétrica do equipamento [\%]

4. Custo total (CT)

$$
C T(R \$)=C M O+C M A+C E
$$

Onde:

$\mathrm{CMO} \rightarrow$ Custo da mão de obra [R\$]

$\mathrm{CMA} \rightarrow$ Custo do metal de adição [R $]$

$\mathrm{CE} \rightarrow$ Custo da energia elétrica $[\mathrm{R} \$]$

A metodologia utilizada para construção do software será mostrada conforme as etapas da Figura 2. 
Figura 2: Representação esquemática das etapas de criação do software

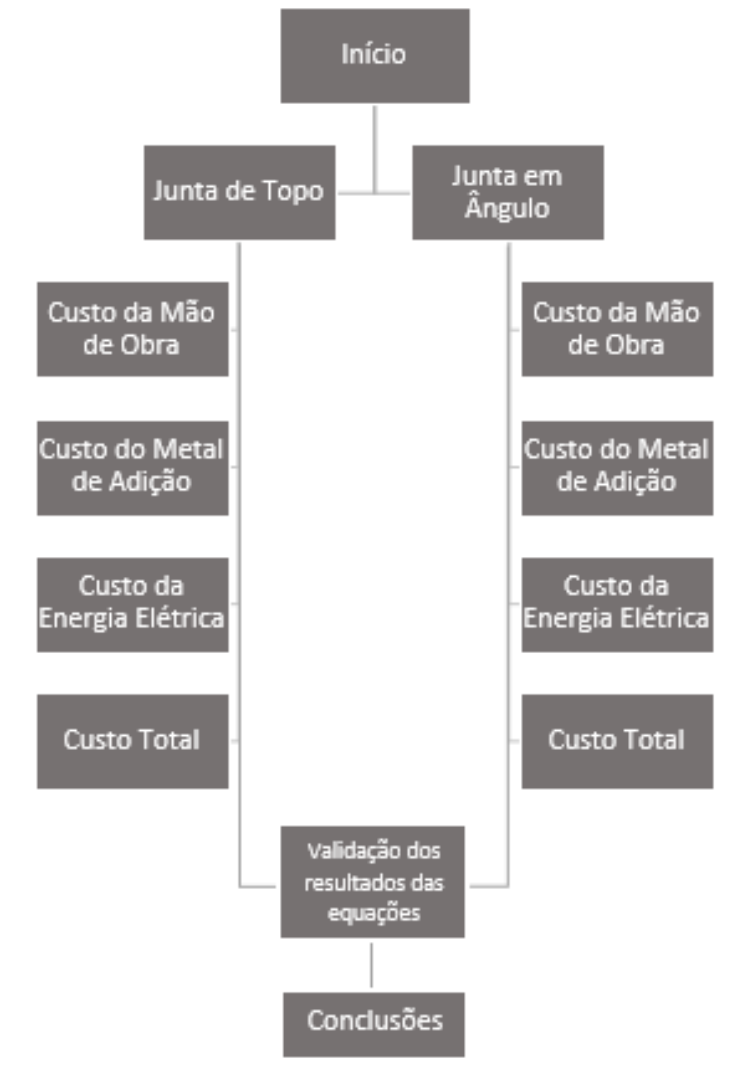

Fonte: AUTOR (2020)

\section{RESULTADOS E DISCUSSÃO}

Num primeiro momento da pesquisa foi feita uma imersão ao processo de soldagem com eletrodos revestidos, tanto com aulas práticas, quanto com estudo teórico. Também é importante ressaltar o aprendizado adquirido a respeito da programação na linguagem Visual Basic, necessário para que o software fosse desenvolvido com sucesso.

Parafraseando LONGO (2006), nos últimos anos o programas computacionais têm sido muito utilizados em quase todos os ramos de atividades, sendo muito importantes para o desenvolvimento de projetos, facilitando a análise de problemas de grande complexidade. Hoje em dia tal recurso se encrontra indispensável e fundamental para realização de tais atividades.

O programa foi desenvolvido na linguagem Visual Basic for Application (VBA) por meio da utilização das diversas ferramentas disponíveis nessa extensão do Microsoft Excel, utilizando-se, também, da criação de códigos para tornar mais prático e fácil o cálculo dos custos envolvidos no processo de soldagem com eletrodo revestido (SMAW), conforme mostrado nas Figuras 3 a 8 . 
Figura 3: Tela inicial do software

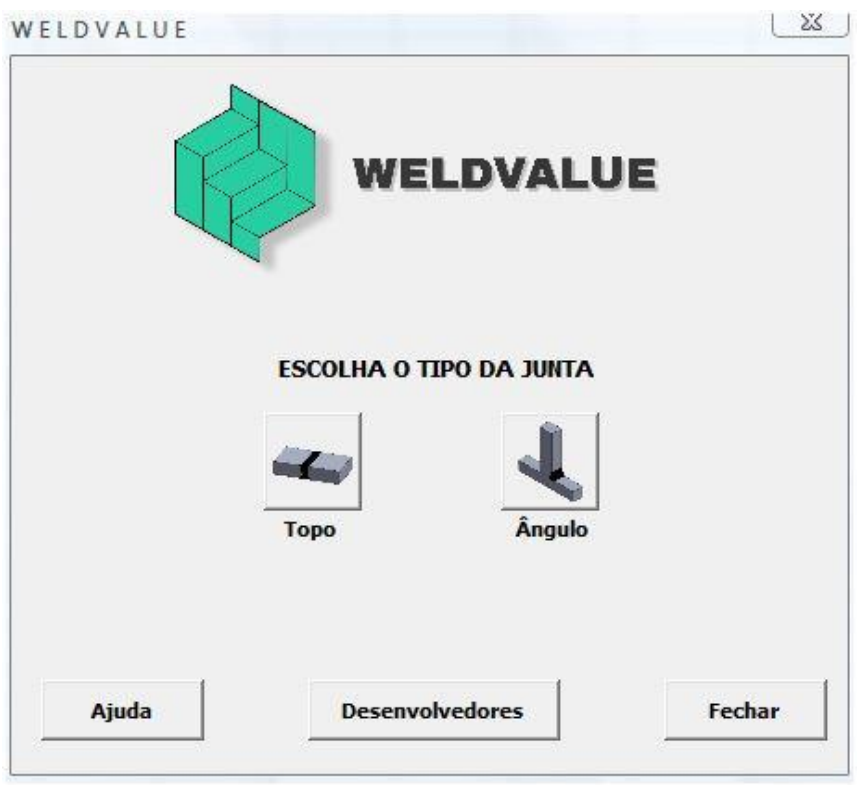

Fonte: AUTOR (2020)

A Figura 3 apresenta a tela inicial do WELDVALUE, onde se pode escolher entre a junta de topo ou ângulo, obter ajuda acerca do funcionamento do software em "Ajuda", conhecer os desenvolvedores em "Desenvolvedores" ou fechar o programa em "Fechar".

Figura 4: Tela de seleção de custos

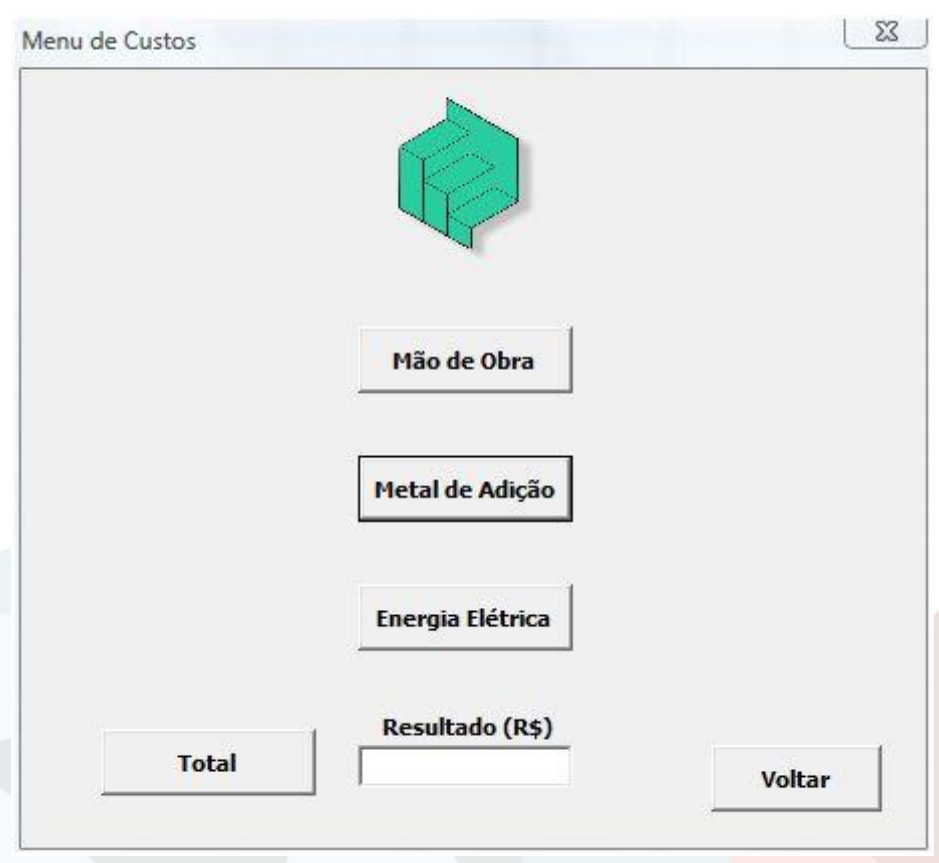

Fonte: AUTOR (2020)

A Figura 4 apresenta a tela de "Menu de Custos", onde há três opções de seleção e uma quarta opção para efetuação do custo total. Essa tela é comum tanto para junta de topo, quanto para junta em ângulo. 
Figura 5: Tela de custo da mão de obra

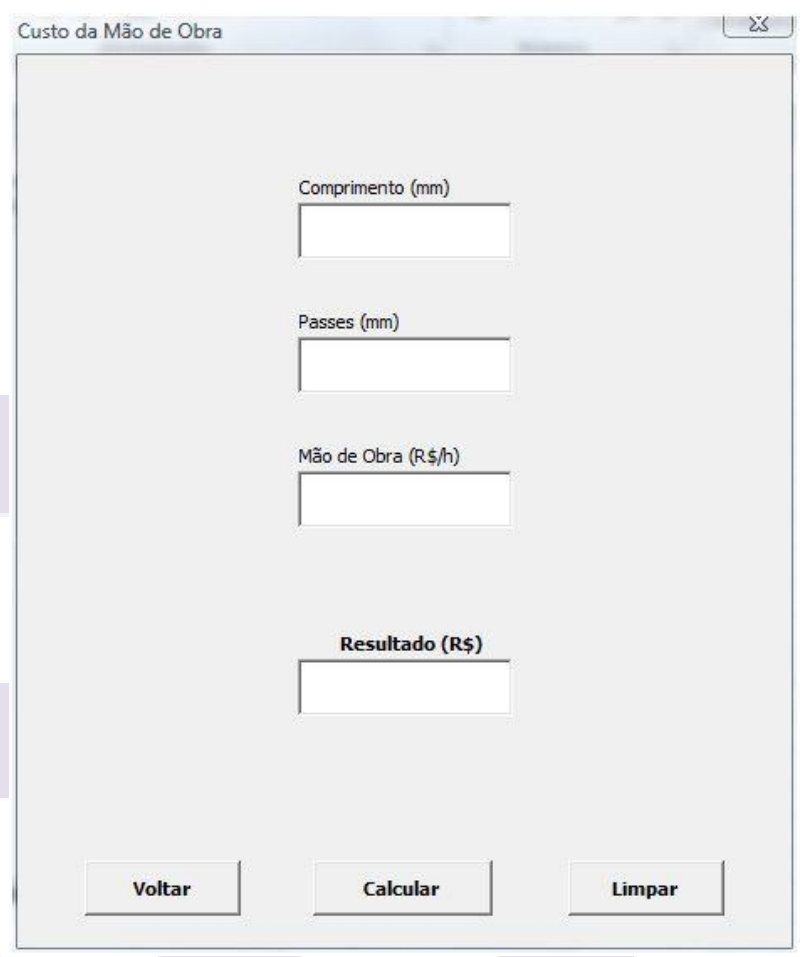

Fonte: AUTOR (2020)

Figura 6: Tela de custo do metal de adição (junta de topo)

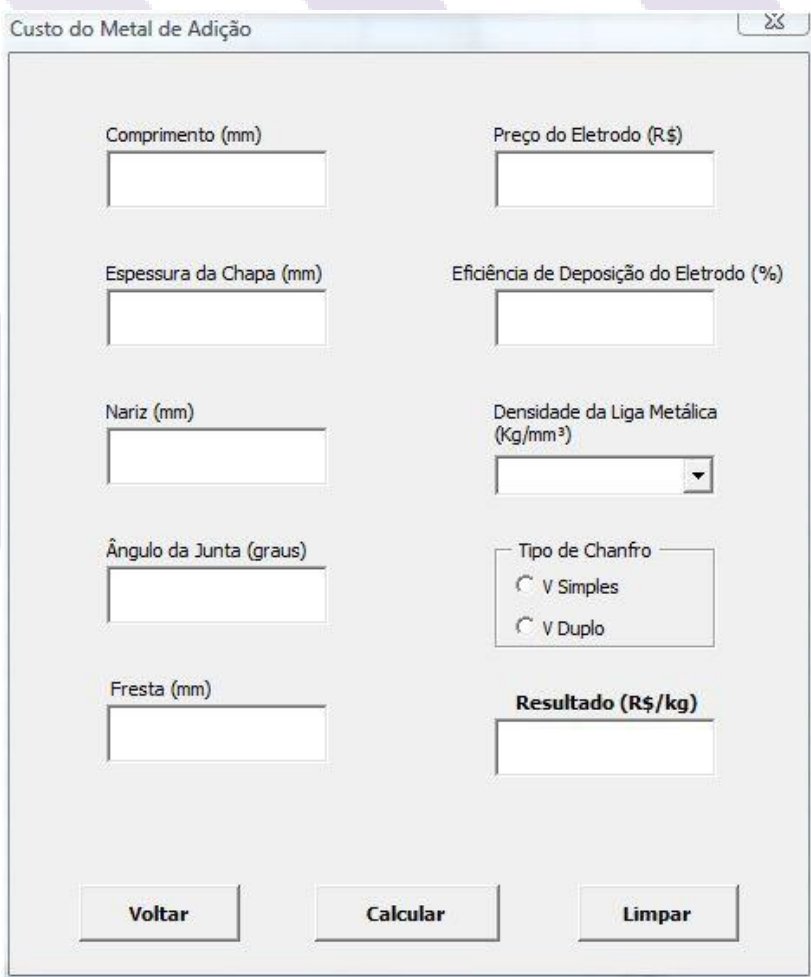

Fonte: AUTOR (2020) 
Figura 7: Tela de custo do metal de adição (junta em ângulo)

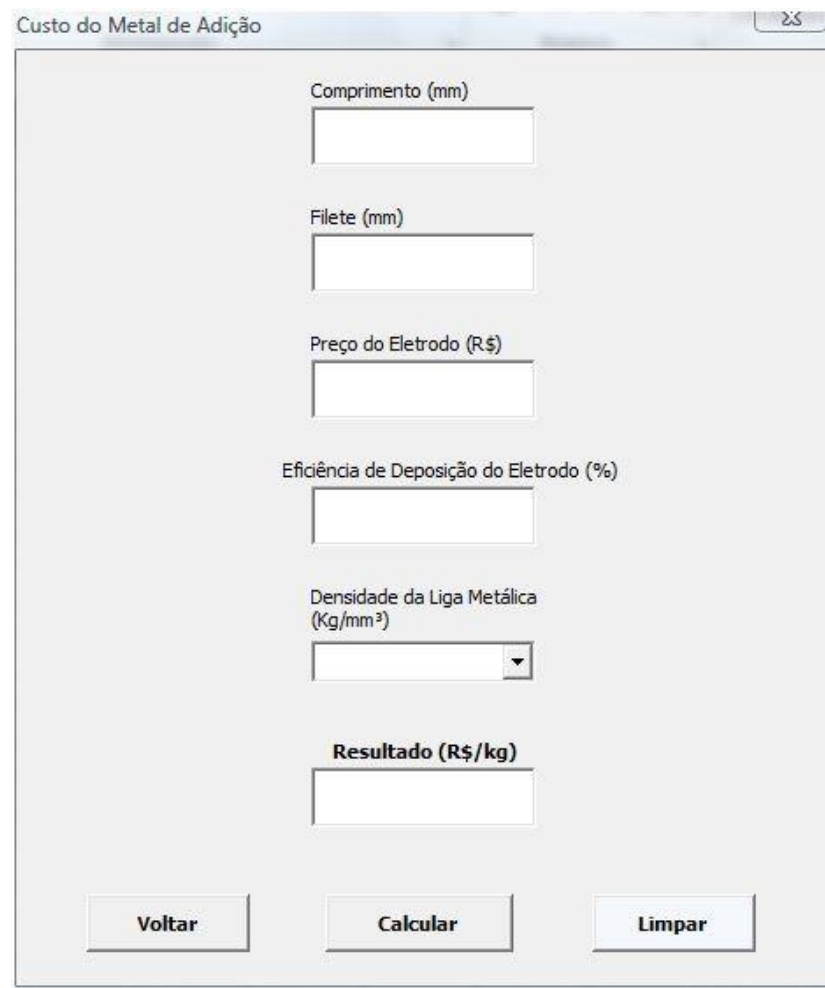

Fonte: AUTOR (2020)

Figura 8: Tela de custo da energia elétrica

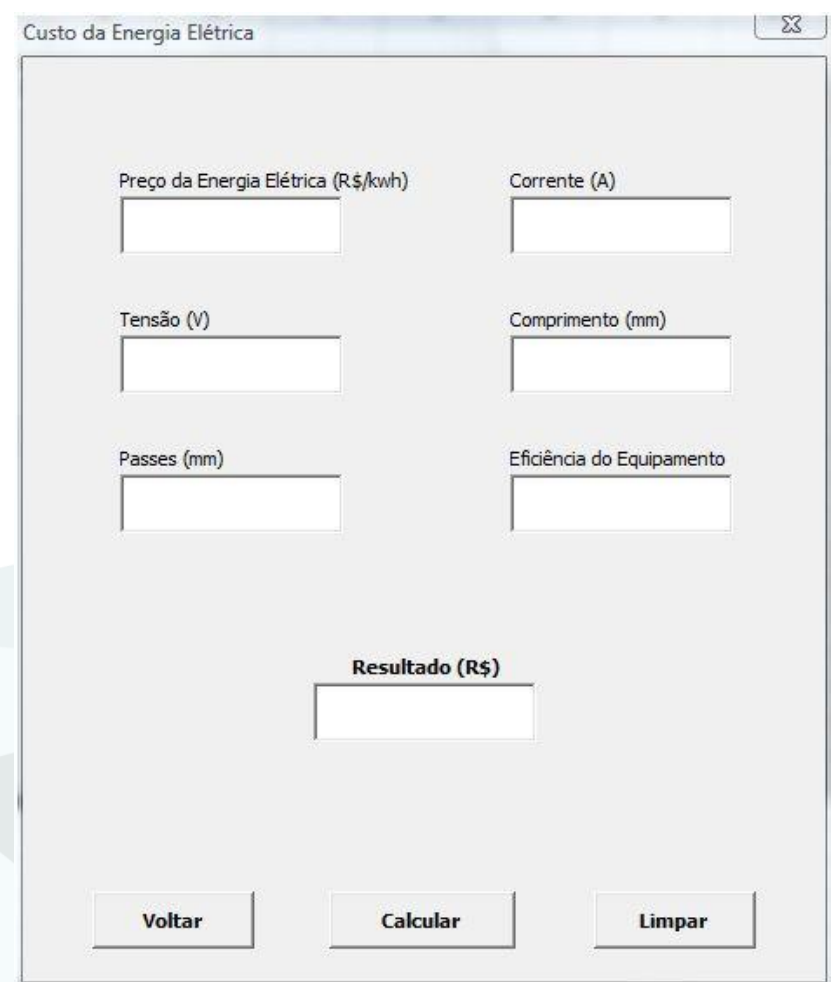

Fonte: AUTOR (2020)

Nas figuras 5 a 8 são apresentadas sub-telas do "Menu de custos", onde é possível 
calcular cada tipo de custo, limpar rapidamente as informações inseridas em "Limpar" ou voltar ao Menu em "Voltar".

A fabricação moderna vem passando por expressivas transformações nas últimas décadas, alicerçadas pelos seguintes fatores: necessidade de se fabricar com o menor custo possível, a busca pela confiabilidade nas medições, dentre outros. Dentro deste contexto, o computador vem exercendo um papel de suma importância no sentido de otimizar todos esses fatores (OLIVEIRA, 2009). Cada vez mais se faz necessário o desenvolvimento de programas computacionais como este, pois possuem um papel fundamental na agilização dos processos produtivos.

\section{Aplicação}

Para uma Junta em Ângulo com as seguintes características:

Comprimento de solda $[\mathrm{mm}]=3000$

Filete $[\mathrm{mm}]=9$

Passes $[\mathrm{mm}]=150$

Mão de obra $[\mathrm{R} \$ \mathrm{~h}]=30$

Preço do eletrodo $[\mathrm{R} \$]=7$

Eficiência de deposição do eletrodo [\%] $=60$

Densidade do material $\left[\mathrm{kg} / \mathrm{mm}^{3}\right]$ - Aço Carbono

Preço da energia elétrica $[\mathrm{R} \$ / \mathrm{kWh}]=0,35$

Tensão $[\mathrm{V}]=25$

Corrente $[\mathrm{A}]=300 \mathrm{AC}$

Eficiência do equipamento $[\%]=75$

Obtiveram-se os seguintes resultados, conforme mostra as Figuras 9 a 12. 
Figura 9: Custo da mão de obra

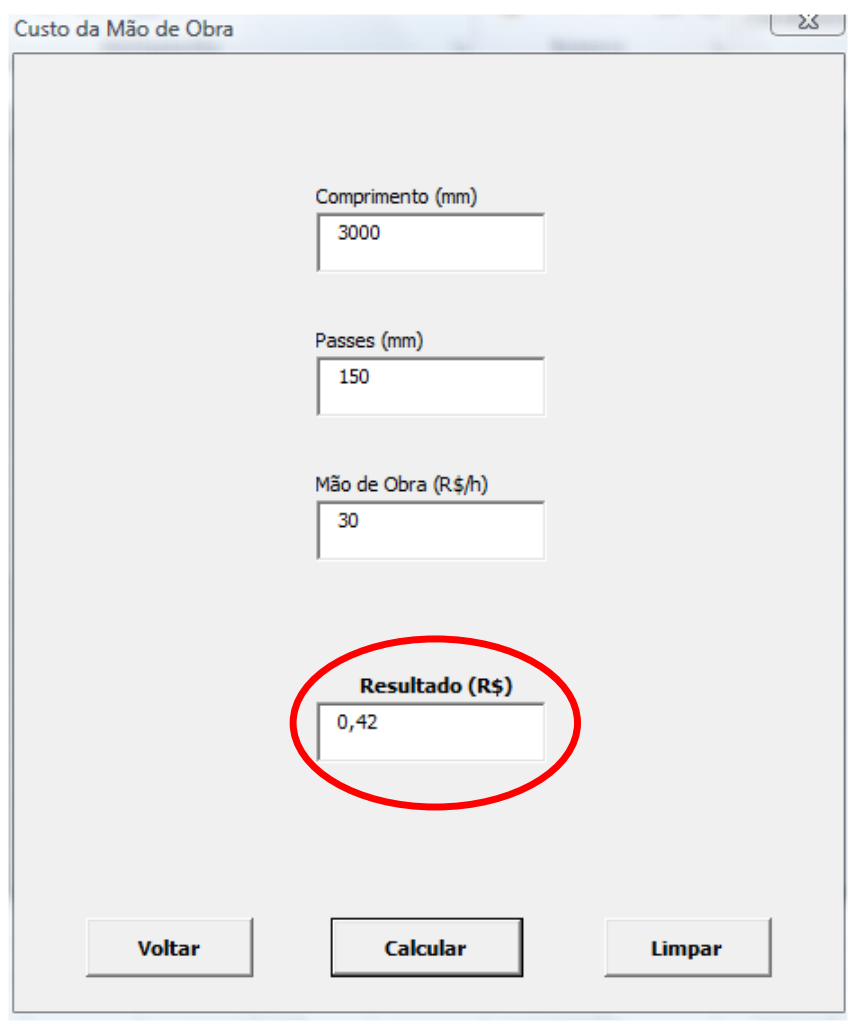

Fonte: AUTOR (2020) 
Figura 10: Custo do metal de adição

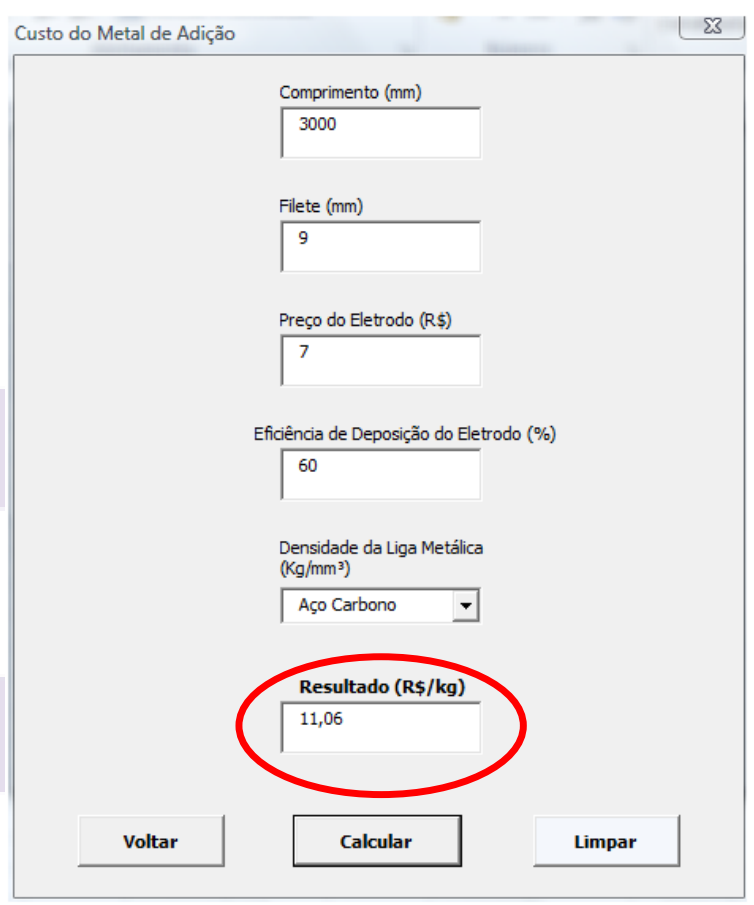

Fonte: AUTOR (2020)

Figura 11: Custo da energia elétrica

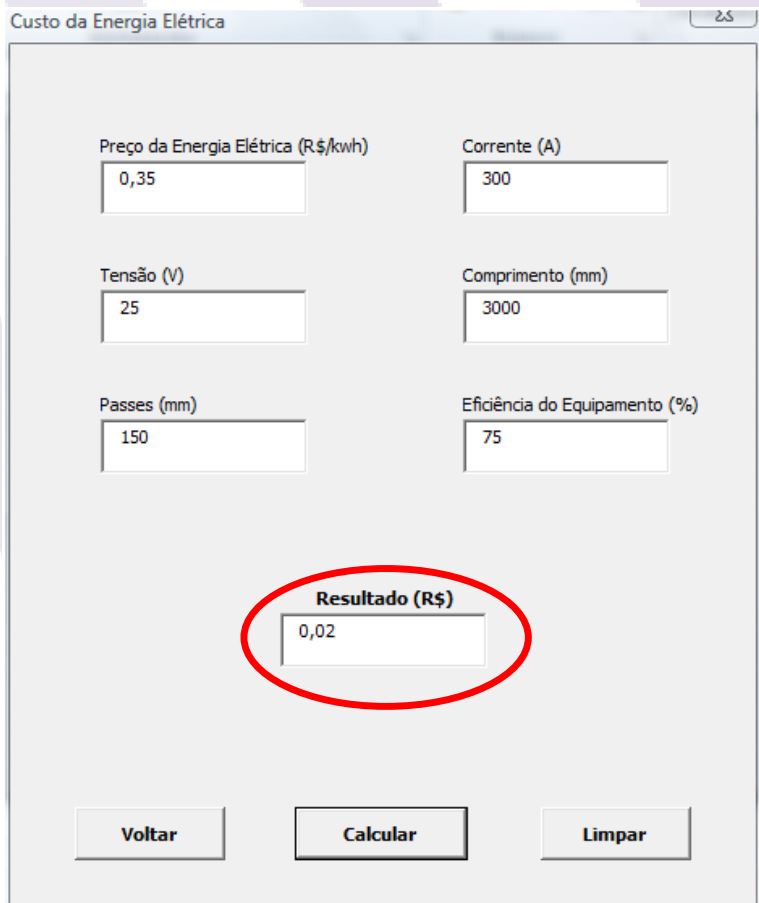

Fonte: AUTOR (2020) 
Figura 12: Custo total

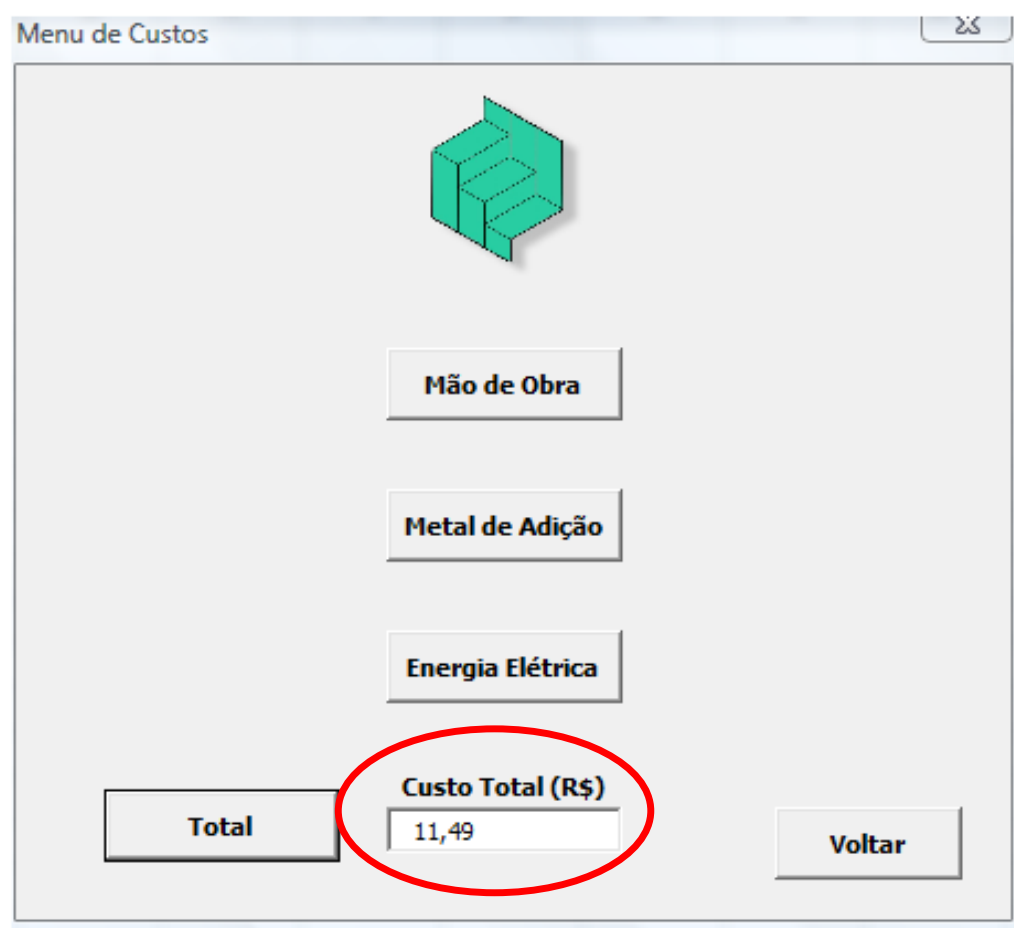

Fonte: AUTOR (2020)

\section{CONCLUSÕES}

Esta pesquisa teve por objetivo desenvolver um programa computacional para cálculo dos custos envolvidos no processo de soldagem com eletrodo revestido (SMAW) com o propósito de facilitar a forma como se determina tais custos.

O software permite que o usuário alcance os resultados apenas inserindo informações básicas como o tipo de chanfro, junta, comprimento da chapa, etc. Depois de um estudo e análise sobre as equações analíticas, foi possível validar os resultados obtidos através de cálculos manuais que comprovaram os resultados obtidos pelo programa. 


\section{REFERÊNCIAS}

EDUARDO FERREIRA DE OLIVEIRA, J. Desenvolvimento de um programa computacional para a integração de dados de projeto, fabricação e medição de peças torneadas com ênfase na síntese de tolerâncias dimensionais determinísticas. Universidade Federal de Pernambuco. Recife, p. 279. 2009.

FORTES, C.; VAZ, C. Eletrodos revestidos OK. ESAB BR, 2005. Disponível em: Acesso em: out. 2018.

GUIMARÃES, P. B.; BARBOSA, P. M. A.; YADAVA, Y. P.; SIQUEIRA FILHO, A. V.; BARBOSA, J. M. A.; FERREIRA, R. A. S. Comparative Study of Levels of Residual Stresses Obtained Numerically as a Function of Welding Current. Anais... 21st International Congress of Mechanical Engineering - COBEM, Natal - RN. pp. 1-8, 2011.

LONGO, H. I. A importância da verificação dos resultados do computador. XXXIV CONGRESSO BRASILEIRO DE ENSINO DE ENGENHARIA. Passo Fundo/RS: [s.n.]. 2006. p. 11.

MARQUES, P. V.; MODENESI, P. J. Introdução aos Processos de Soldagem. Universidade Federal de Minas Gerais. Belo Horizonte, p. 52. 2000.

MARQUES, P. V.; MODENESI, P. J.; BRACARENSE, A. Q. Soldagem: Fundamentos e Tecnologia. 3. ed. Belo Horizonte: UFMG, 2011. 363 p.

MODENESI, P. J. Estimativa de Custos em Soldagem. Universidade Federal de Minas Gerais. Belo Horizonte, p. 7. 2001. 